\title{
Attitudes towards Suicide in the Adolescent Population
}

Urška Arnautovska, BS-Psych

received an Award for the best final thesis by Faculty of Arts of University of Ljubljana, written under the mentorship of Prof. Dr. O. T. Grad and Prof. J. Bečaj. She is continuing with a postgraduate study of clinical psychology in Ljubljana and is currently working at the Australian Institute for Suicide Research and Prevention at Griffith University in Brisbane, Australia.

Onja T. Grad, PhD

is a clinical psychologist, family therapist and supervisor, working at the University Psychiatric Hospital mostly with the survivors after the death of a relative and also as a professor at the Medical School, University of Ljubljana, Slovenia. She contributed some chapters on suicide bereaved to the international books, edited and co-authored a few national books on people in distress and published international articles on clinicians after suicide of their patient. 
Abstract

Background. Only few studies have so far confirmed the clear connection of attitudes towards suicide with prevalence of suicidal behavior and there are several contradictory findings on the balance of this relationship. Slovenia has long had a very high suicide rate, including the population of adolescents. Aims. The aim of this study was to examine attitudes of Slovene adolescents towards suicide and their connection to different suicide risk factors. Methods. A Questionnaire on Attitudes towards Suicide was put forward to 423 high school students from three regions based on the different regional suicide rates. Results. The results proved our expectation of girls having more permissive attitudes towards suicide than boys as well as that permissive attitude was positively associated with the majority of suicide risk factors. Conclusions. With respect to certain limitations of the study we discuss the implications of the main finding, being that permissive attitudes towards suicide are more likely a risk than a safety factor for suicidal behavior.

Keywords: attitudes towards suicide, permissiveness, adolescents, suicide risk factor 


\section{INTRODUCTION}

\section{Attitudes towards suicide}

Attitudes are the key concept in the socio-psychological model of explaining and predicting human behaviour and social construction of the world around us (Rus, 1997). They are defined as lasting cognitive, emotional and active predispositions towards a certain object (Nastran Ule, 1997).

Throughout history, there have been different cultural conceptualizations of suicide. For a more detailed view on that the reader is referred to the work of Hawton and van Heeringen (2000).

The first definition of attitudes towards suicide was presented by Bayet as early as 1922 (Salander Renberg, 1998). He defined them as two basic positions: morale simple represents condemnation of suicide under any circumstances, while morale nonceé a more accepting and permissive attitude, namely understanding it under specific conditions, without approving of it at the same time. Only in the 80's did studies begin to report of the variations of attitudes towards suicide regarding the gender of the respondent, the victim and the type of suicidal behaviour (Deluty, 1988). Findings of the studies about the relationship between attitudes towards suicide and suicidal behaviour so far depend mostly on the level of the analysis they are being based on.

At the individual level of the analysis, the great majority of the studies show a positive association between the two: individuals with any kind of suicidal behaviour have more tolerant and understandable attitudes towards suicide (Garcia Falconi, 2003; Marcenko, Fishman \& Friedman, 1999; Salander Renberg, 1998; Kerkhof \& Natawat, 1989). This was confirmed also by the 25 year-long longitudinal study in 
New Zealand with a birth cohort of more than 1000 children (Beautrais, Horwood \& Fergusson, 2004). There are, however, a few exceptions showing the opposite (Ramsey \& Bagley, 1985).

On the other hand, at the societal level, lower suicide rates were found in the morale simple group, the one with more rejecting attitudes towards suicide in comparison with the morale nonceé position of attitudes (Bayet, 1922 in Salander Renberg, 1998). Contrary to this founding, the longitudinal study of Salander Renberg and Jacobsson in Sweden (2001) showed a decline of suicide rates from 1981 to 1990 , while at the same time, the attitudes towards suicide changed towards greater permissiveness. The same was found by Platt (1989) in Scotland, who suggested that people in a more hostile atmosphere in general need to act in more extreme forms to get the desirable response from others.

\section{Attitudes towards suicide and suicide risk factors}

With regard to gender, men are quite constantly reported to have more tolerant attitudes towards suicide than women (Dahlen \& Canetto, 2002).

The studies exploring attitudes towards suicide among different age groups report of different findings. In Canada for example Boldt (1982) found more permissive attitudes among young in comparison to their parents, while some other researchers (Segal et al, 2004) showed the opposite. In any case, it remains unclear whether different attitudes towards suicide between young and adults are the result of generational or chronological changes.

Regarding religion, Mehmet (2004), in his study on Turkish adolescents with religiously based education, found that they were less likely to accept suicide as an option and also reported less suicidal thoughts than the control group. 
Apart from suicide risk factors some researchers (Arnautovska, 2008) focused on person's life satisfaction and found it negatively connected with permissive attitude towards suicide and other (Zadravec, 2006) were investigating the social presentations about suicide in different populations and professions.

It looks as the relationship between attitudes towards suicide and suicidal behaviour is too complex to come to one universal conclusion. Nevertheless, it is clear, that attitudes towards suicide affect people's attitudes towards helping suicidal people and more importantly their own help-seeking behaviour.

The aim of the present research was to explore the attitudes towards suicide in the population of Slovene adolescents.

It was predicted that the adolescents would have permissive and tolerating attitudes towards suicide, would believe in its prevention and be prepared to talk about it. This prediction was based on predominating psychosocial processes and tasks of the adolescent developmental period, one of those being the forming of a personal identity, which usually includes an active exploration stadium (Erickson, 1983).

It was further expected that male participants would be more understanding and tolerant towards suicide than their female counterparts.

On the basis of previous studies at the individual level of research, it was also hypothesized that a permissive attitude towards suicide would be positively connected to all types of adolescents' suicide behaviour. In accordance with we expected that certain suicide risk factors would be present in participants with more permissive attitudes in a greater extent. 


\section{METHODOLOGY}

\section{Participants}

The sample included 423 Slovene adolescents, 107 being male and 165 female, with a mean age of 18.3 years $(S D=1.0 ; \min =16$; $\max =26$ years $)$. Data was collected in three different Slovenian cities with a high, medium and low suicide rate respectively; Celje $(n=121)$, Ljubljana $(n=193)$ and Koper $(n=109)$.

In each city, we randomly chose some comprehensive grammar schools ( $n=$ $274)$ and one local four-year vocational and technical school $(n=130)$ and one local PUM Program $(n=19)$, which is a public acknowledged program for young people, who have, for different reasons, left the general educational system and are therefore more at risk towards suicidal behaviour (PUM, 2000).

\section{Procedure}

Written requests were sent to the school's counselors, explaining the nature and aim of the research. All schools, except one, gave their permission and devoted one school hour per class in order to carry out the study. Researchers themselves explained the purpose of the study to the participants, assured them the confidentiality of their answers and asked them to answer honestly. Each participant first completed the ATTS questionnaire, then the questions about suicidal behaviour, and finally questions regarding personal data. 


\section{Materials and criteria}

A Questionnaire on Attitudes towards Suicide (ATTS) developed by Salander Renberg and Jacobsson (2003) on a Swedish population and translated into Slovene language by a research group included in the project AER (Assembly of European Regions). ATTS includes 37 statements about suicidal behaviour with a five-point Likert answering scale. Since the items in our sample sorted differently than in the Swedish general population sample, we applied our own explorative factor analysis. The coefficients of internal consistency and amount of total variance explained for each factor are reported in the Appendix. The six extracted factors include the following suicide-related attitudes and beliefs: (1) Permissiveness - people have the right to take their own life and acceptance of suicide in the situation of incurable disease; (2) Preventability - suicide can and must be prevented; Incomprehensibility - suicide cannot be justified or understood; (4) Avoidance of taking - talking about suicide triggers suicidal thoughts which stay with a person forever; (5) Unpredictability - suicide happens without any warning and people who talk about suicide do not usually commit it; and (6) Loneliness \& appeal - loneliness is the reason for suicide and an attempt of suicide is mostly a cry for help. Answers were ranked as follows:”5-I strongly agree”, “4-I agree”, “3-I cannot decide”, “2-I do not agree” and “1-I strongly disagree”. The higher scores therefore represent grater agreement with the belief expressed by each factor.

Questions about the presence of suicidal behaviour controlled the presence of suicidal ideations, plans and suicide attempts in the adolescent as well as of his surroundings, being the participant's family and separately friends or other known people. 
The self-reported probability of committing suicide in the future was measured on a scale of 10 , with $0 \%$ meaning it is impossible to commit suicide and $100 \%$ meaning the person was sure to do it.

Personal data included information about the gender of a participant, area of living, school grades in the previous year of high school, family status, including parents' education. 


\section{RESULTS}

Using the explorative factor analysis of items of ATTS different criteria were considered in order to extract the most reliable and meaningful solution. Starting from Kaiser-Guttmann Criterion that proposed a three-factor solution, the further factorization of these factors implicated the existence of six factors. Before factorization, six items which were not stable in any of the different factor solutions were excluded, namely 4, 7, 15, 17, 31 and 35. A principal component analysis was conducted on the remaining 32 items using a varimax rotation. Since the internal consistency of particularly the last three factors was rather poor, we focused our analysis mostly on the first factor, Permissiveness.

Mean scores of items assigned by factor analysis to each factor were calculated and in future analysis taken as a measure of the attitude expressed by that factor. The greatest agreement of participants was found with items of Preventability $(M=3.97, S D=.57)$ and the most rejecting with Avoidance of talking $(M=2.75, S D$ $=.62)$. Besides the latter, only Permissiveness $(M=2.98, S D=.72)$ had a mean score smaller than the neutral score (three). In all other factors, the mean score was directed towards agreement with the attitude expressed by each factor: Incomprehensibility ( $M$ $=3.14, S D=.72)$, Loneliness \& appeal $(M=3.14, S D=.80)$ and Unpredictability $(M$ $=3.34, S D=.58)$.

To investigate the differences between genders independent samples MannWhitney U test was applied. Boys and girls differed significantly $(p<.05)$ in factors of Loneliness \& appeal $\left(M_{\text {boys }}=3.03, S D=.85 ; M_{\text {girls }}=3.22 S D=.75\right)$, Preventability $\left(M_{\text {boys }}=3.88, S D=.60 ; M_{\text {girls }}=4.04, S D=.53\right)$ and Permissiveness $\left(M_{\text {boys }}=3.07, S D\right.$ $\left.=.78 ; M_{\text {girls }}=2.92 S D=.66\right)$. 
Table 1. Independent Samples Test (Mann-Whitney U test for Equality of Means) for Mean Item Score on Permissiveness in Groups regarding the Presence of Different Types of Suicide Behaviour of an Adolescent.

\begin{tabular}{lcccccc}
\hline & & $n$ & $M$ & $S D$ & $z$ value & $p$ value \\
\hline Suicide ideations & yes & 191 & 3.11 & .69 & -4.3 & .00 \\
& no & 232 & 2.82 & .72 & & \\
Suicide plans & yes & 107 & 3.24 & .72 & -4.37 & .00 \\
\multirow{5}{*}{ Suicide attempt } & no & 316 & 2.89 & .69 & & \\
& yes & 33 & 3.26 & .69 & -2.07 & .04 \\
& no & 330 & 2.96 & .71 & & \\
\hline
\end{tabular}
of mean scores on all of the subgroups $(p<.05)$ except in the group without suicide ideations $(p>.05)$.

** suicide ideations: answers "rare” to “often"; suicide plans: answers "rare” to "often”; suicide attempt: one or more suicide attempts. 
The participants who reported the experience of any type of suicidal behaviour had significantly more permissive attitudes towards suicide than those who did not report it (Table 1). The Spearman's rho coefficient of correlation confirmed that permissiveness towards suicide was significantly positively $(p<.05)$ correlated with adolescents' reports of either suicidal ideation $(r=.26)$, plans $(r=.23)$, suicide attempt $(r=.10)$ as well as adolescents' self reported probability of suicide ( $r=.32, p$ $<.01)$

It the case of suicidal behaviour in the adolescent's surroundings, the division into pairs of groups was already done by direct answers (“yes” /”no”). No significant differences (with $p<.05$ ) were found in permissiveness towards suicide between the compared pairs of groups. However, in order to observe the trend of attitudes in these groups, the results are presented in Figure 1.

\section{Insert Figure 1}

Figure 1. Mean item scores on Permissiveness regarding the presence of different types of suicidal behaviour in the participant's family and among friends or other known people.

${ }^{*} \mathrm{CE}=$ Celje, $\mathrm{LJ}=$ Ljubljana, $\mathrm{KP}=$ Koper; $\mathrm{SR}=$ suicide rate.

To test whether permissiveness towards suicide is positively connected with certain suicide risk factors, a one-way ANOVA was conducted with the dependent variables being the area of living (representing the prevalence of suicide) and gender, and the independent the mean item score on factor Permissiveness. The acceptance of suicide differed among the areas, $F(2,418)=3.69, p<.05$, as well as in interaction of 
area with gender, $F(1,418)=2.40, p<.05$. The absolute differences of these groups are shown in Figure 2.

\section{Insert Figure 2}

Figure 2. Mean item scores on Permissiveness regarding the area of living and gender *SR = suicide rate; $\mathrm{CE}=$ Celje, $\mathrm{LJ}=$ Ljubljana, $\mathrm{KP}=$ Koper $_{\mathrm{m}}=$ men $_{\mathrm{f}}=$ female.

A one-way ANOVA with the same dependent variable was also conducted, whereby the gender and type of school were controlled. The participants' permissive attitude towards suicide was different with respect to the type of school, $F(2,418)=$ 3.47, $p<.05$ and in interaction with gender, $F(1,418)=3.82, p<.05$. The most rejecting attitude was held by the adolescents attending technical schools $(M=2.83$, $S D=.65)$, attitudes towards suicide in general high schools were quite ambivalent ( $M$ $=3.04, S D=.72$ ), while the most permissive attitude was held by those attending a special educational program $(M=3.14, S D=.91)$.

Grades in the previous year of education did not prove to differentiate between more or less permissive attitudes towards suicide, as was proved with Mann Whitney U test for independent samples $(p=.20)$.

A Kruskal-Wallis' test further showed that neither the father's $\left(\chi^{2}=5.19, p=\right.$ .16) nor the mother's education $\left(\chi^{2}=2.41, p=.49\right)$ was significant enough for the nature of adolescents' attitudes.

For the last factor, we controlled the structure of the family; a one-way ANOVA confirmed its importance on participants' permissiveness towards suicide, $F(2,404)=3.10, p=.05$. Adolescents with divorced parents had the most permissive attitudes towards suicide ( $n=51, M=3.15, S D=.75)$, the groups with parents living 
together had, on average, ambivalent attitudes ( $n=341, M=2.95, S D=.71)$, while the ones with an experience of death in the family were towards suicide the most rejecting $(n=12, M=2.76, S D=.64)$. 


\section{DISCUSSION}

The aim of the present study was to better understand the nature of attitudes towards suicide in the adolescent population and to explore whether the permissive attitude could potentially be a risk or a protective factor for suicidal behaviour. The ATTS questionnaire was applied as the main instrument. We focused on the first factor, Permissiveness, which expresses the person's tolerance and acceptance of suicide (especially in situations of incurable disease) and the belief that suicide is a human right.

On the basis of 423 adolescents’ answers, we cannot say whether their attitude towards suicide was permissive or rejecting, because they were in average choosing the neutral, "I cannot decide", option. Anyhow, the adolescents believe in prevention of suicide and are prepared to talk about it. These findings speak in favour of the implementation of directed preventive programs toward youth suicide at this age. A more pro-preventive attitude of younger persons, aged 18 to 35, towards suicide was as well found in the Swedish population (Salander Renberg \& Jacobsson, 1998).

The significant differences between male and female attitudes towards suicide are consistent with our predictions: the trend of boys' attitude pointed in the direction of permissiveness while the trend of girls' towards rejection of suicide. This kind of gender specific attitude was also reported in the adult population in other countries (Dahlen \& Canetto, 2002; Salander Renberg \& Jacobsson, 2001). Consistent with the studies linking the male gender role and negative attitudes toward help-seeking (Berman, 2005) was also the fact that in our study, on average, girls agreed more with the statement "I am prepared to help a person in a suicidal crisis by establishing contact" than boys did. This means that female participants believed more in suicide 
prevention and also expressed greater preparedness to reach out to a suicidal individual.

As it was expected, permissiveness was further positively related to adolescents' report of own suicidal behaviour. The most tolerating attitudes towards suicide were found amongst adolescents who had experienced a suicide attempt and those who had previously planned a suicide. Those who did not report about any type of suicidal behaviour had on the contrary significantly more restrictive attitudes. Although one must remain cautious about the deceptive causality among permissiveness towards suicide and past or future suicidal behaviour, it was shown that permissiveness was from all the variables that involved suicidal behaviour, the most strongly related exactly to subjective probability of own future suicide.

Although family history of suicidal behaviour should increase suicide risk (Cerel \& Roberts, 2005), this study did not confirm this. Perhaps the information on past mental history of the participants or their parents' might clarify this relationship. Still, the quantity of different types of suicidal behaviour among friends or other known people was, in spite of a weak connection $(r=.10, p<.05)$, positively correlated with permissiveness.

The results (Figure 2) confirm that permissiveness is positively related also to the prevalence of suicide; the most permissive attitudes towards suicide were those of the adolescents living in the area with a high prevalence of suicidal behaviour (Celje) and the most rejecting ones were those from the area of low prevalence of suicide (Koper). The finding is contradictory to the results of the Swedish postal study using the same questionnaire (Salander Renberg \& Jacobsson, 2001), but on the other hand consistent with the relationship that was found by Bayet in 1922 (in Salander Renber, 1998) and other studies (Ramsey \& Bagley, 1985). 
More permissive attitudes towards suicide were found in adolescents attending a special learning program. These adolescents left the regular school system and were lonely, thus more vulnerable to suicidal behaviour.

An interesting finding of this study is that adolescents with divorced parents had the most permissive attitudes towards suicide, while the most rejecting were the ones who had experienced the death of one or both parents. The finding that family structure is related to adolescents' attitudes towards suicide also corresponds with other studies (Ruangkanchanasetr et al, 2005).

\section{Limitations}

The first limitation to the study arise from unsatisfactory psychometric characteristics of the ATTS questionnaire. It looks as the instrument is not reliable enough to be used in the same form with different age groups or even different cultural settings. Although M. Kocmur (2003) with SUIATT also found quite ambivalent attitudes towards suicide in the sample of Slovenian students, it remains unclear whether this could be assigned to poor differential characteristics of the instruments.

The instrument also measures different components of attitudes, which are not clearly divided in the divison of items into factors. Factor Preventability, for example, includes a cognitive (the beliefs about suicide prevention) as well as a dynamic component (the preparedness to prevent suicide). The results, however, implicate that they are not necessarily congruent with each other.

The most reliable factor, Permissiveness, should be interpretated mostly as an attitude towards suicide in the event of an uncurable disease, widely known as euthanasia. Since different situations evoke more or less understanding in the 
respondents (Dahlen \& Canetto, 2002), it could be expected that permissiveness of suicide in other situations might be different as in the case of a difficult disease.

Although a permissive attitude towards suicide as an act might seem less preventing for suicidal behaviour, the same should not be transmitted to attitudes toward suicidal people. There is evidence that young people with religious education held less permissive attitudes towards suicide but were at the same time more understanding towards a person with suicidal thoughts than the group with secular education (Mehmet, 2004). This divison should be considered in future studies when testing the construct validity of the instruments measuring the attitudes towards suicide.

Generalisation of the findings is limited by self-reporting of suicidal behaviour. Persons who held a more permissive attitude towards suicide might as well more likely report of own sucidal behaviour, which could bias the findings.

Finally, the sample of adolescents attending the special program for school »drop outs « was too small to allow any generalisations to other suicidally more vulnerable people. Furthermore, the total size of the sample in the present study is too specific and heterogenous in order to apply the characteristics of attitudes towards suicide from this study on all the adolescent population.

\section{Implications}

The main implication of this study is that permissive attitudes towards suicide are more likely to be a risk than a safety factor for suicidal behaviour of an adolescent. This preposition is confirmed by significant positive relations of tolerant attitudes towards suicide with the following: an adolescent's self-reported history of suicidal behaviour and probability of future suicide, high suicide rate in the area of living, and experience of divorced parents. This implication is contrary to the 
permissive aspect of the society that encourages people to talk openly about their problems, including suicidal thoughts, which is sometimes regarded as having the preventive effect on suicide rates (Kerkhof \& Natawat, 1989). Looking at it from the psychodynamic perspective (Praper, 1999), it could be said that the rejection of suicide is parallel to the concept of (personal) borders, which after all, provide security needed for a self-regulated and self-protected functioning.

It is possible that various studies also use different concepts of permissiveness. In this study the relationship of factor Permissiveness and Avoidance of talking was found to be positive ( $r=.14, p<.05$ ), which means that people who avoid talking about suicide are more tolerant towards it than those who are prepared to talk about it. Predisposing that permissiveness is actually a risk factor for suicidal behaviour, the findings of our study suggest that talking about suicidal behaviour should not be avoided.

The implications of these findings for self inflicted injuries as opposed to suicide behaviour should still be tested, since these two behaviours have somehow different goals and meanings.

Considering that public attitudes are strongly connected to people's social presentations which help to create social reality (Černigoj, 2000), the risk of permissiveness should be implemented into media by preventive guidelines, stating that there are better solutions to solving problems than suicide.

\section{Conclusions}

The current study consistently shows that permissive attitude towards suicide is significantly positively connected with many aspects of suicidal behaviour of the adolescent. This implicates that a permissive attitude towards suicide could be a risk factor for suicidal behaviour. Interestingly, the risk effect of such social attitudes 
towards suicidal behaviour has been indirectly indicated already by Durkheim's anomic suicide (1992), that he used in order to describe suicide due to a lack of regulation in social structures (gr. »anomia« = »lawlessness «). Since the media have a clear attitude forming, orienting influence on people and can play a decisive role in causing self-destruction (Fekete, Schmidtke, Takahashi, Etzersdorfer, Upanne \& Osvath, 2001), these findings are especially important for developing media guidelines regarding suicidal behaviour. The threat is that some presentations of suicide by the media may produce a familiarity with the idea of suicide showing suicide as an acceptable alternative solution to life stresses (Gould \& Schaffer, 1986). 


\section{REFERENCES}

Arnautovska, U. (2008). Stališča mladostnikov do samomorilnega vedenja: sprejemljivost samomorilnega vedenja kot dejavnik tveganja [Attitudes of adolescents toward suicidal behaviour: permissiveness of suicidal behaviour as a risk factor]. Psihološka obzorja, 17 (1), 41-55.

Beautrais, A.L., Horwood, L.J., \& Fergusson, D.M. (2004). Knowledge and attitudes about suicide in 25-year-olds. Australian and New Zealand Journal of Psychiatry, 38 (4), 260-265.

Berman, L. (2005). Help-seeking among men: implications for suicide prevention. Pogled. The View, 3 (1-2), 36-51.

Boldt, M. (1982). Normative evaluation of suicide and death: A cross-generational study. Omega, 132, 145-157.

Cerel, J., \& Roberts, T.A. (2005). Suicidal behaviour in the family and adolescent risk behaviour. Journal of Adolescent Health, 36 (4), 352.

Černigoj, M. (2000). Predstavitev in kritika teorije socialnih predstav [The theory of social representations: overview and critique]. Psihološka obzorja, 9 (1), 23-38.

Dahlen, E.R., \& Canetto, S.S. (2002). The role of gender and suicide precipitant in attitudes toward nonfatal suicidal behavior. Death Studies, 26 (2), 99-116.

Deluty, R. H. (1988). Factors Affecting the Acceptability of Suicide. Omega: Journal of Death and Dying, 19 (4), 315-326.

Durkheim, E. (1992). Samomor. Prepoved incesta in njeni izviri [The suicide, the prohibition of incest and its origins]. Ljubljana: Filozofska fakulteta.

Erikson, E. H. (1983). Identity: youth and crisis. London, Boston: Faber and Faber. 
Fekete, S., Schmidtke, A., Takahashi, Y., Etzersdorfer, E., Upanne, M., \& Osvath, P. (2001). Mass Media, Cultural Attitudes, and Suicide: Results of an International Comparative Study. Crisis: The Journal of Crisis Intervention and Suicide Prevention, 22 (4), 170-172.

Garcia Falconi, R. (2003). Suicidal ideation: The role of demographic, religious and psychological variables. Revista Mexicana de Psicologia, 20 (1), 75-82.

Gould M, \& Schaffer D. (1986). The impact of suicide in television movies: Evidence of imitation. New England Journal of Medicine, 315, 690-694.

Hawton, K., \& van Heeringen, K. (2000). The international handbook of suicide and attempted suicide. Chichester: Wiley.

Kerkhof, A. J. F. M. \& Natawat, S. (1989). Suicidal behavior and attitudes towards suicide among students in India and the Netherlands. A cross-cultural comparison. In R. F. W. Diekstra, S. R. Maris, S. Platt, A. Schmidtke \& G. Sonnek (Ed.), Suicide and its prevention: the role of attitude and imitation, (pp. 108-143). Leiden, New York: E.J. Brill.

Kocmur, M. (2003). Attitudes towards suicide in Slovenia: A cross-sectional survey. International Journal of Social Psychiatry, 49 (1), 8-16.

Marcenko, M.O, Fishman, G., \& Friedman, J. (1999). Reexamining adolescent suicidal ideation: A developmental perspective applied to a diverse population. Journal of Youth and Adolescence, 28 (1), 121-138.

Mehmet, E. (2004). The effects of religious versus secular education on suicide ideation and suicidal attitudes in adolescents in Turkey. Social Psychiatry and Psychiatric Epidemiology, 39 (7), 536-542.

Nastran Ule, M. (1997). Temelji socialne psihologije [Essentials of social psychology]. Ljubljana: Znanstveno in publicistično središče. 
Platt, S. (1989). A subculture of parasuicide? In R. F. W. Diekstra, S. R. Maris, S. Platt, A. Schmidtke \& G. Sonnek (Ed.), Suicide and its prevention: the role of attitude and imitation, (pp. 108-143). Leiden, New York: E.J. Brill.

Praper, P. (1999). Razvojna analitična psihoterapija [Developmental analytic psychotherapy]. Ljubljana: Inštitut za klinično psihologijo.

PUM (2000). Izobraževanje odraslih. Projektno učenje za mlajše odrasle [Adult education. The project learning for young adults]. Ljubljana: Ministrstvo za šolstvo in šport, Zavod RS za šolstvo.

Ramsey, R., \& Bagley, C. (1985). The prevalence of suicidal behaviors, attitudes and associated social experiences in an urban population. Suicide and LifeThreatening Behavior, 15, 151-167.

Rus, V.S. (1997). Socialna psihologija: teorija, empirija, eksperiment in uporaba II [Social psychology: theory, practise, experiment and use II]. Ljubljana: Davean d.o.o.

Ruangkanchanasetr, S., Plitponkarnpim, A., Hetrakul, P., \& Kongsakon, R. (2005). Youth risk behavior survey: Bangkok, Thailand. Journal of Adolescent Health, 36 (3), 227-235.

Salander Renberg, E. (1998). Perspectives on the suicide problem - from attitudes to complited suicide. Umeå: Umeå University Medical Dissertations.

Salander Renberg, E., \& Jacobsson, L. (2001). A European Collaboration project in Prevention of Suicide. Attitudes towards suicide in the general population. In O.T. Grad (Ed.), Suicide risk and Protective Factors in the New Millenium (pp. 269272). Ljubljana: Cankarjev dom.

Salander Renberg, E., \& Jacobsson, L. (2003). Development of a Questionnaire on Attitudes Towards Suicide (ATTS) and Its Application in a Swedish Population. Suicide and Life-Threatening Behavior, 33 (1), 52-64. 
Segal, D.L., Mincic, M.S., Coolidge, F.L., \& O'Riley, A. (2004). Attitudes toward suicide and suicidal risk among younger and older persons. Death Studies, 28 (7), 671-678.

Zadravec, T. (2006). Expert and Lay Explanations of Suicidal Behaviour: Comparison of the General Population's, Suicide Attempters', General Practitioners' and Psychiatrists' Views. The International Journal of Social Psychiatry, 52 (6), 535551. 


\section{APPENDIX, QUESTIONNAIRE ON ATTITUDES}

\section{TOWARDS SUICIDE (ATTS)}

TABLE 3.

Obtained factors, explained total variance (\% ETV), items, loadings and internal consistency (Cronbachs $\alpha$ ) for the ATTS questionnaire

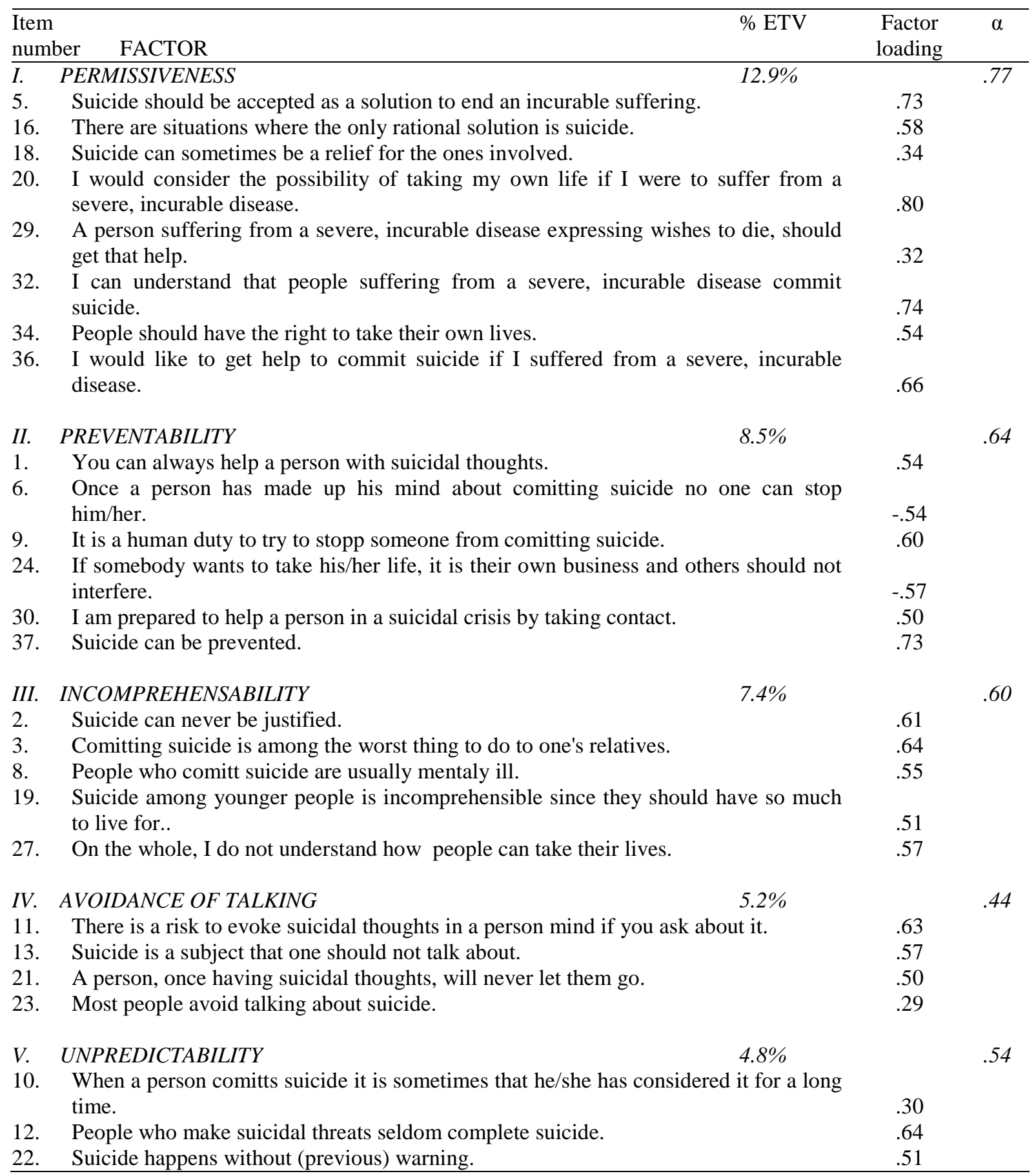


28. Relatives have usually no idea about what is going on when a person is thinking about suicide.

33. People who talk about suicide do not commit suicide.

VI. LONELINESS \& APPEAL

$4.1 \%$

14. Loneliness could for me be a reason to take my life.

25. It is mainly loneliness that drives people to commit suicide.

.79

26. A suicide attempt is essentially a cry for help.

.50 